\title{
Research on the design of freeway toll station
}

\author{
Bo Sun ${ }^{1, a, *}$,Fuchang Huo ${ }^{2, b}$ \\ ${ }^{1}$ Department of Computer Science and Technology, Changchun University of Science and \\ Technology, Changchun 130022, China; \\ ${ }^{2}$ College of Science, Changchun University of Science and Technology, Changchun 130022, \\ China; \\ a461744460@qq.com, bc_network@163.com \\ *corresponding author
}

\begin{abstract}
With the increase of traffic flow, in order to improve capacity, the shape of the toll plaza, the size of the design has become particularly important, the toll plaza that can improve the capacity of toll booths, ease the congestion situation and reduce the traffic accident is more and more favored by builders. In response to the traffic situation of the New Jersey Expressway, we analyze the existing toll plaza, and on the basis of it, we design the shape of the toll plaza by establishing the mathematical model. In this model, we consider the three important factors of accident prevention, throughput and cost. We establish the safety evaluation model, the capacity model and the cost minimization model, and finally determine the shape and size of the toll plaza.Of course, we also conducted a simulation of the cellular automata and sensitivity analysis of our model to enhance the applicability of the model. Inevitably, there are many shortcomings in our model, in the end, we propose areas for improvement and future prospects.
\end{abstract}

Keywords .The toll plaza ,The safety evaluation model , The capacity model ,The cost minim ization model ,Tandem toll station ,Reversible electronic toll lane

\section{Introduction}

With the rapid growth of car ownership and the rapid arrival of motorized society, public expectations and demands for highway traffic services continue to rise, traffic congestion and security issues are increasingly being highly concerned about and gradually become a social problem.

With the gradual formation of the highway network, more and more nations such as China are building their own networks of superhighways, and they are turning to the tollbooth to foot the bill. But one undeniable drawback to tolling that is the bane of drivers and road builders alike: When traffic is thick, cars back up in line to get to the tollbooths, and after paying their tolls, drivers lose time scrambi- ng for position as the many lanes exiting the toll plaza merge together, returning the road to its original width.

In order to get rid of the long lines, it is common sense to provide as many tollbooths as possible will minimize the toll payment delay, but more tollbooths mean more merging and hence more congestion after the tolls are paid.And a new problem appeared. How drivers can safely merge lanes after paying toll. In this paper we will investigate the question of choosing a better construction program of the toll plaza to get an optimal balance between these two factors.

In doing so, we will analyze the situation from a qualitative point of view to determine what part of the problem we should try to model, what we should ignore, and what components of the system should follow the rules, and the establishment of a safety evaluation model of highway toll station. Then we will be able to apply some results such as queue theory ,cellular automata and so on, to derive a means of computing the performance level for a toll plaza given the number of initial lanes, number of tollbooths, safety factor and traffic flow level, from which we will be able to determine,giving a better construction 
program of the toll plaza.

\section{Models}

\subsection{The model of toll plaza}

\subsubsection{Assumption}

1. The toll lanes have no effect on each other

2. Vehicles entering the fast-track of electronic tolls have no effect on other vehicles

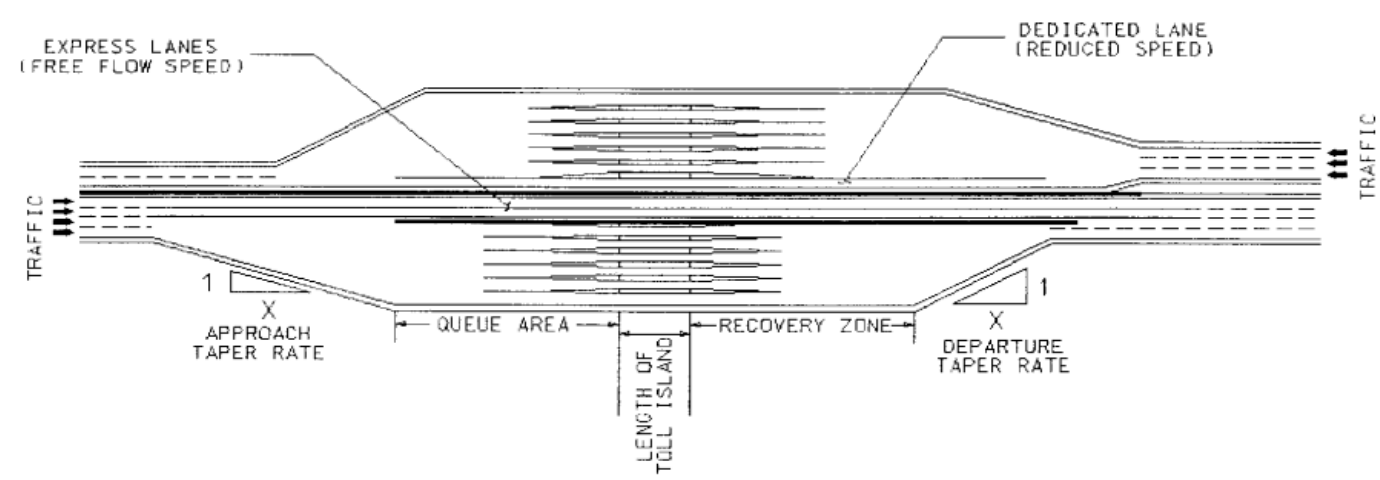

FIG. 1. Toll Plaza Elements-Plan View

\subsubsection{Taper Rates}

A modification of the equations used by the 1993 Revisionto the MUTCD for Temporary Traffic Control Lane Additions(FHWA 1993) is proposed for setting toll plaza approach tapers These tapers are proposed only for the area of roadway where the presence of vehicles anticipated to stop for toll payment exists (1-4).The proposed equations for diverge tapers are as follows:

$60 \mathrm{~km} / \mathrm{h}$ or less

$$
L=W S^{2} / 290
$$

$70 \mathrm{~km} / \mathrm{h}$ or more

$$
L=0.23 W S
$$

where $L=$ minimum length of taper in meters; $S$ = posted or statutory approach speed in $\mathrm{km} / \mathrm{h}$; and $W=$ offset distance in meters.

$$
L=W S^{2} / 105
$$

$45 \mathrm{mi} / \mathrm{h}$ or more

$$
L=\frac{3}{8} W S
$$

where $L=$ minimum length of taper in feet; $S=$ posted or statutory approach speed in $\mathrm{mi} / \mathrm{h}$; and $W=$ offset distance in feet

\subsubsection{Departure Tapers (Merge)}

After vehicles pass the toll plaza, the numerous toll plaza lanes are normally reduced to a typical roadway section or bridge section ${ }^{[2]}$. The proposed equations for merge tapers are as follows:

$60 \mathrm{~km} / \mathrm{h}$ or less

$$
L=(1.5) \frac{W S^{2}}{290}+5 W
$$

where $L=$ minimum length of taper in meters; $S=$ posted or statutory approach speed in $\mathrm{km} / \mathrm{h}$; and $W=$ offset distance in meters.

$40 \mathrm{mi} / \mathrm{h}$ or less

$$
L=(1.5) \frac{W S^{2}}{105}+5 W
$$

where $L=$ minimum length of taper in feet; $S=$ posted or statutory approach speed in $\mathrm{mi} / \mathrm{h}$; and $W=$ offset distance in feet. 


\subsubsection{Transition Lengths}

The transition lengths for a toll plaza are located on theapproach and the departure. The components of the design between the tapers and a toll plaza are the tangent queue area and the recovery zone, as shown in Fig. 1

\subsubsection{Queue Area}

From the point of view of the arrival of toll station vehicle Should all arrive at the toll station vehicle $^{[4]}$, from the beginning of the line charges to pay off the bills, once again, on the freeway, the total time spent as little as possible ${ }^{[3]}$.

The total elapsed time of vehicles at the toll station consists of two parts:

(1) The average time delay by vehicles from the queue to pay $T_{\boldsymbol{q}}(\boldsymbol{n})$

(2) After leaving the toll booth, at the height of the vehicle, waiting to enter into the driveway of the average time delay $\boldsymbol{T}_{\boldsymbol{k}}(\boldsymbol{n})$

While the total residence time of vehicles at the toll station:

$$
T(n)=T_{q}(n)+T_{k}(n)
$$

From the point of view of the shortest residence time of expectation, the establishment of model:

$$
\begin{gathered}
\min T(n)=T_{q}(n)+T_{k}(n) \\
s t\left\{\begin{array}{l}
\rho<1, \quad \rho_{k}<1 \\
T_{q}(n)=\frac{\rho^{n+1}}{(n-1) !(n-\rho)^{2}} P_{0} / \lambda \\
T_{k}(n)=\left(\rho_{k}^{2} \times m\right) /\left(n \times \mu \times\left(1-\rho_{k}\right)\right) \\
P_{0}=\left[\sum_{i=0}^{n} \frac{\rho^{i}}{i !}+\frac{\rho^{n+1}}{n !(n-\rho)}\right]^{-1}
\end{array}\right.
\end{gathered}
$$

Of which: $\mu$ per unit of time the number of vehicles released from a toll booth,

$\lambda_{k}$ That the k-th Lane per unit time can be adopted by the average traffic flow, said that the level of the load of the k-th after leaving the toll road

$$
p_{k}=\frac{n \times \mu}{m \times \lambda_{k}}
$$

\subsubsection{Recovery Zone}

The recovery zone varied among various toll authorities and did not seem to directly relate to the approach speed of the roadway. In most cases, the recovery zone was equal to or less than the length used for the queue area. In the case of trucks and trailers, the length should be designed to double the normal case ${ }^{[5]}$.

Table 1. Recommended Toll Plaza Lane Widths

\begin{tabular}{|c|c|}
\hline Lane type & Lanes width(m/ft) \\
\hline Wide load lane & Consult state regulations(4.3-5.5m or 14-18ft) \\
\hline ETC express lanes & $\begin{array}{c}\text { Normal roadway width(usually two 3.6m or } 12 \mathrm{ft} \\
\text { lanes)with shoulders }\end{array}$ \\
\hline Dedicated ETC lanes & $3.6 \mathrm{~m}$ or $12 \mathrm{ft}$ \\
\hline Lanes with high truck traffic(\%trucks $>30 \%)$ & $3.6 \mathrm{~m}$ or $12 \mathrm{ft}$ \\
\hline $\begin{array}{c}\text { Lanes with substantial truck } \\
\text { traffic(30\% }>\% \text { trucks }>10 \%)\end{array}$ & $3.3 \mathrm{~m}$ or $11 \mathrm{ft}$ \\
\hline All other lanes & $3.0 \mathrm{~m}$ or $10 \mathrm{ft}$ \\
\hline
\end{tabular}

Costs of a toll plaza

$\mathrm{n}_{1}$ The number of ETC toll lanes

$\mathrm{n}_{2}$ The number of other lanes

a The width of ETC toll lanes

b The width of other lanes 
d The width of highway

11 Length of queue area

12 Length of recovery zone

c Construction cost per unit area

m Taper rates follows

Then, according to our design of the shape of the toll plaza, we can get square area as

So ,the cost of toll plaza is

$$
\mathrm{S}=(11+\mathrm{l} 2) *(n 1 * a+n 2 * b)+(d+n 1 * a+n 2 * b) * m
$$

$$
\mathrm{C}=\mathrm{S}^{*} \mathrm{C}
$$

\subsection{The model of accident prevention}

\subsection{1 safety evaluation model of highway toll station}

Many studies have shown that the traffic design index and operating parameters of expressway toll station are related to the traffic safety of toll station. Therefore, a number of toll station design indexes and the relationship between operating parameters and safety are established accordingly, which can be used as an evaluation method for highway toll station traffic safety.

Based on the analysis of highway toll station security factors, taking into account the ease of data collection and the reliability of the results and toll station traffic flow characteristics, we select the toll square gradient rate(s), the service level of the toll station(V/C), and the slope of longitudinal gradient of toll plaza entrance (i) as the model parameters, and the number of toll stations in traffic accidents as a standard safety assessment model, the establishment of safety evaluation model of highway toll station by regression analysis of the data sample.So we will get:

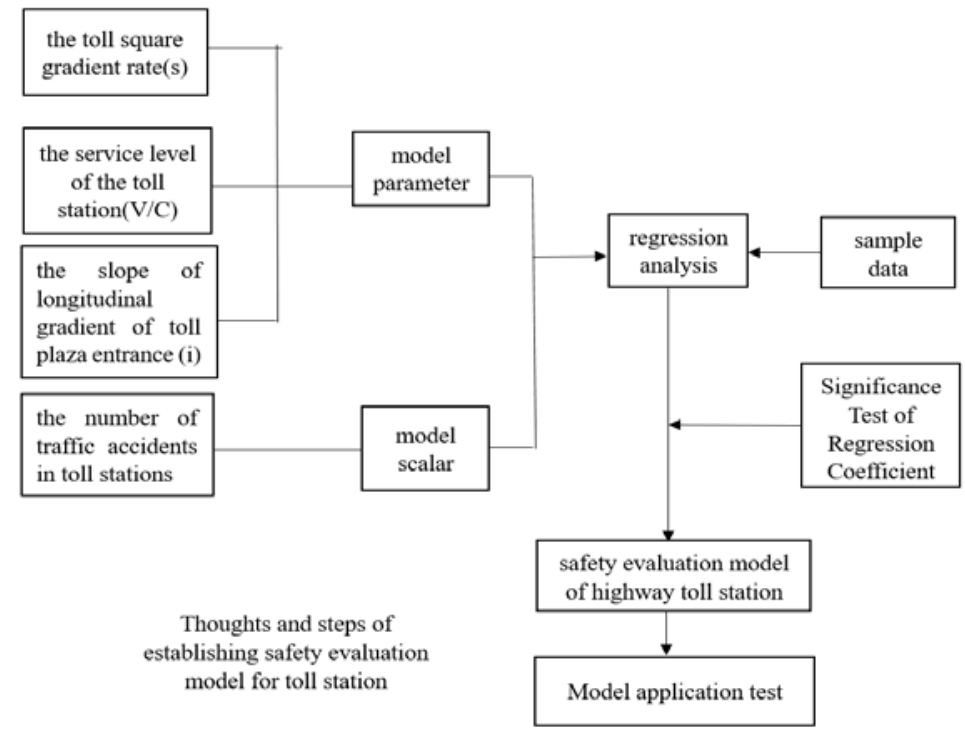

Fig 2 model of design process

So we can describe the highway toll station based on highway traffic control parameters and traffic toll station traffic safety evaluation model is written as:

In the above formula,

$$
\mathrm{Y}=\mathrm{F}\left(\mathrm{X}_{1}, \mathrm{X}_{2}, \mathrm{X}_{3}\right)
$$

Y: the number of traffic accidents in toll stations

$\mathrm{X}_{1}: 1 / \mathrm{s}, \mathrm{L}$ is the toll square gradient rate

$\mathrm{X}_{2}: \mathrm{V} / \mathrm{C}$, the service level of the toll station

$\mathrm{X}_{3}: \mathrm{i}$, the slope of longitudinal gradient of toll plaza entrance

$\mathrm{F}()$ :mathematical expression

In order to make the toll station security evaluation model not only satisfy the need of solving practical problems, but also make the solution method simple and practical, the model equation adopts linear expression: 


$$
Y=\beta_{0}+\beta_{1} X 1+\beta_{2} X_{2}+\beta_{3} X_{3}
$$

\subsubsection{A Regression Analysis Method for Model}

We assume that sample size is $\mathrm{N}$, and we use $\mathrm{Y}_{\mathrm{i}}(\mathrm{i}=1,2,3 \ldots \mathrm{N})$ to represent the $\mathrm{Y}$ value of the $\mathrm{i}$-th sample, and use $\mathrm{X}_{1, \mathrm{i}}, \mathrm{X}_{2, \mathrm{i}}, \mathrm{X}_{3, \mathrm{i}} \ldots \mathrm{X}_{\mathrm{n}, \mathrm{i}}(\mathrm{i}=1,2,3 \ldots \mathrm{N})$ to represent the value of each variable in the i-th sample.

According to the assumptions, at every junction we have:

$$
Y=\left[\begin{array}{c}
Y_{1} \\
Y_{2} \\
Y_{3} \\
\vdots \\
Y_{n}
\end{array}\right], X=\left[\begin{array}{cccc}
1 & X_{1,1} & \cdots & X_{n, 1} \\
1 & X_{1,2} & \cdots & X_{n, 2} \\
1 & X_{1,3} & \cdots & X_{n, 3} \\
\vdots & \vdots & \vdots & \vdots \\
1 & X_{1, n} & \cdots & X_{n, n}
\end{array}\right], \beta=\left[\begin{array}{c}
\beta_{1} \\
\beta_{2} \\
\beta_{3} \\
\vdots \\
\beta_{n}
\end{array}\right]
$$

Plugging (2.15) into the equation for (2.16),we obtain : $Y=X \beta$

Then, using the maximum likelihood estimation to estimate the parameters of each variable, a normal equation group is obtained:

$$
X^{T} X \beta=X^{T} Y
$$

Then the maximum likelihood estimate of the matrix is:

$$
\hat{\beta}=\left(X^{T} X\right)^{-1} X^{T} Y
$$

So we can get the following regression equation:

$$
\hat{Y}=\hat{\beta}_{0}+\hat{\beta}_{1} \times X_{1}+\hat{\beta}_{2} \times X_{2}+\hat{\beta}_{3} \times X_{3}
$$

After solving the equation, it is necessary to make a significant test of its linear assumption and the regression coefficient of each variable, and there can not be multiple linear problems among the variables.

\subsection{Traffic Capacity}

\subsubsection{The traffic capacity of a single charging door}

The mouth of a flat fee for each lane of the establishment of a toll gate (Figure 1), SP is the location of the services of a vehicle detection, the location of the card or check card charges, waiting for the location of WP refers to the location of one of the car up and down the driveway.
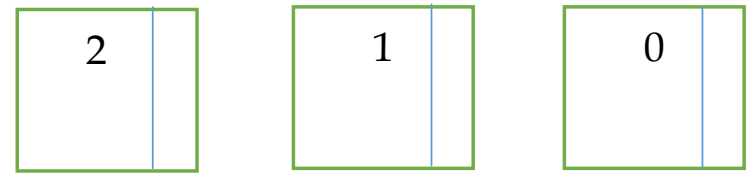

Fig 3 a single charging door

From the beginning SP of will on the part of vehicle, if set to 1 when the car left the SP, the time between 1 car and 0 car from the front for:

$$
\mathrm{H}=\mathrm{H}_{0}+\mathrm{S}
$$

In the summations: The $\mathrm{H}_{0}-0$ thThe front of the car to leave the SP distance, The $\mathrm{S}$ - 1 thThe service hours of the car.

Under normal circumstances:

$$
\mathrm{H}_{0}=\mathrm{R}+\mathrm{M}
$$

In the summations: R-Reaction time, Is the No. 0 Car to leave the car began to enter the SP and 1 sp elapsed time between the moment; $\mathrm{M}$ - Forward time, Refers to the location of the vehicle from the wait to enter the time required for service location.

If one car for each.The front is random variation,The method of the mathematical expectation $\mathrm{E}(\mathrm{H})$ :

$$
\mathrm{E}(\mathrm{H})=\mathrm{E}\left(\mathrm{H}_{0}\right)+\mathrm{E}(\mathrm{S})=\mathrm{E}(\mathrm{R})+\mathrm{E}(\mathrm{M})+\mathrm{E}(\mathrm{S})
$$

Every car is in accordance with the distance from the front of the procession, so every capacity of toll-lane C—— E (H) countdown:

$$
\mathrm{C}=\frac{1}{E(H)}
$$




\subsubsection{Multi-channel traffic capacity}

From the above analysis: In the case of multi-channel, select $\mathrm{M} / \mathrm{G} / \mathrm{K}$ queuing model can well describe the state of the actual operation of toll station, here are the $\mathrm{M} / \mathrm{G} / \mathrm{K}$ formulas for calculating statistical parameters of the model.

The average queuing time:

$$
W q=\frac{D(S+G)+E(S+G) 2}{2 E(S+G)+K-\lambda E(S+G)} \cdot 1+\sum_{i=0}^{\mathrm{k}-1} \frac{(K-1) ! K-\lambda E(S+G)}{i ! \lambda E(S+G) k-1}
$$

The average length of stay: $\mathrm{W}=\mathrm{E}(\mathrm{S}+\mathrm{G})+\mathrm{Wq}$

Average queue length:

$$
L q=\frac{\lambda D(S+G)+\lambda(E(S+G)) 2}{2 E(S+G)+K-\lambda E(S+G)} \cdot 1+\sum_{i=0}^{\mathrm{k}-1} \frac{(K-1) ! K-\lambda E(S+G)}{i ! \lambda E(S+G) k-1}
$$

Because the service time and leave time both obeys the normal distribution, the establishment of the formula below ${ }^{[9]}$ :

$$
\begin{aligned}
& E(S+G)=E S+E G \\
& D(S+G)=D S+D G
\end{aligned}
$$

In the summations: $\lambda$ Average strength of the car; $K$ The number of toll-lane;

E(S) Expected service time; $E(G)$ Expected time of departure; $D(S)$ The variance of service time; $D(G)$ The variance of the time of departure;

According to $\mathrm{M} / \mathrm{G} / \mathrm{K}$ queuing theory model The use of the toll the expectation and variance of service time and the time of departure, We can calculate a variety of toll station in different degree of toll-lane and queue can handle the maximum number of vehicles.

\subsection{Analogue simulation}

In order to verify the feasibility of the model,we adopt a cellular automata based traffic flow microscopic simulation model, using this model to effectively coordinate and control the traffic near the toll plaza. Through this model, we can clearly understand the traffic situation of each toll plaza, so as to take effective measures to ensure the smooth flow of the road.

\subsubsection{Simulation system structure diagram}

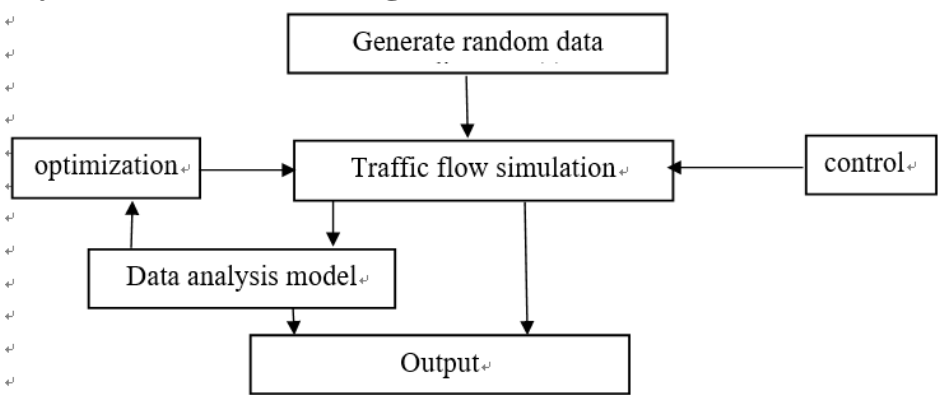

\subsubsection{Operation result}

Fig 4 diagram of the process
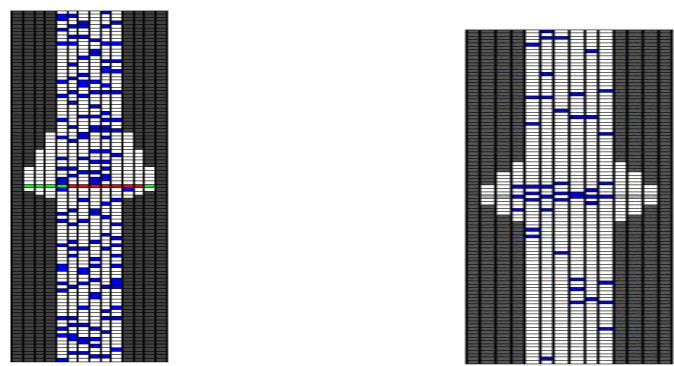

Fig 5 simulation result

\section{Conclusions}

\subsection{Methods used in our models}

With the standard setting of our model, we are set up the model of toll plaza, the design 
guidelines presented in this research include toll plaza approach taper rates, departure taper rates, queue area length, recovery zone length, toll lane widths.And we adopt safety evaluation model of highway toll station for accident prevention. Then we carried out a simulation to verify the feasibility of the model.Finally we analyze the results and improve the model.

Based on the discussion above, we recommend to use one tollbooth per incoming lane when the service rate of toll collection is very high. Otherwise, we suggest to choose the optimal toll method and the situation of the tolling square, depending on the traffic condition.

\subsection{Future Work}

As we all know that a barrier toll is a row of tollbooths placed across the highway, perpendicular to the direction of traffic flow. There are usually more tollbooths than there are incoming lanes of traffic. So when exiting the tollbooths in a barrier toll, vehicles must "fan in" from the larger number of tollbooth egress lanes to the smaller number of regular travel lanes. A toll plaza is the area of the highway needed to facilitate the barrier toll, consisting of the fan-out area before the barrier toll, the toll barrier itself, and the fan-in area after the toll barrier.

If we have the new toll plaza,we will have a higher charging efficiency and a more secure model.We've added side lane to increase safety factor and use Tandem toll station to save time and increase the efficiency of toll charge.We could also increase in the lounge and gas stations on both sides of the road, as well as a variety of consumer entertainment.In this way we not only can play the role of shunt can also increase the overall revenue of the toll plaza.Therefore a new type of toll plaza based on the original has a greater competitive advantage in the market.In the future, I believe the toll plaza will be more competitive.

\section{References}

[1] Agboh,Dennis K. and Anthony A. Saka, Assessment of the Impact of Electronic Toll Collection on Mobile Emissions in the Baltimore Area, National Transportation Center,Baltimore,2000

[2] Gross, Donald and Carl M.Harris, Fundamentals of Queuing Theory, Wiley,New York,1998

[3] Edie, L. C.,"'Traffic delays at toll booths”, Journal of Operations Research Society of America 2(1954) 107-138

[4] Institute of Transportation Engineers, Traffic Engineering Handbook, Ed. James L. Pline, Prentice Hall, Englewood Cliffs, NJ, 1992

[5] Hall R. Tandem Toll Booths for the Golden Gate Bridge, Research Report UCB - ITS RR - 82-7, Institute of Transportation studies,Univ of California,1982

[6] McDonald, D. R., Jr. "Development of toll plaza design guide-lines and creation of a toll plaza design model,” Phd thesis, Vanderbilt University,Nashville, Tenn., Publication No. AAT 9944570. Bell \& Howell Publishers.

[7] Transportation Research Board (TRB). Highway capacity manual special report 209, 3rd Ed., Washington, D.C. 1998

[8] David R. Mcdonald Jr. and Robert E.Stammer Jr., Members, ASCE. Contribution to the development of guidelines for toll plaza design,2001

[9] Federal Highway Administration (FHWA). Manual on uniform traffic control devices millenium edition, U.S. Department of Transportation, U.S. Government Printing Office, Washington, D.C. 2000 